\title{
Seleção de váriavel resposta para determinação de sensibilidade de isolados de Alternaria spp a Boscalida
}

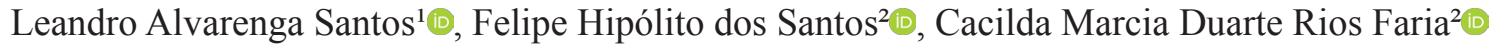

${ }^{1}$ Universidade Estadual de Feira de Santana - UEFS, Av. Transnordestina, s/n, Novo Horizonte - BA, 44036-900, Brasil. ${ }^{2}$ Universidade Estadual do Centro Oeste - UNICENTRO, R. Simeão Varela de Sá, 03 - Vila Carli, Guarapuava - PR, Brasil, 85040-080.

Autor para correspondência: Leandro Alvarenga Santos (leandro.alvarenga.s@hotmail.com)

Data de chegada: 18/12/2016. Aceito para publicação em: 30/01/2019.

\section{RESUMO}

$10.1590 / 0100-5405 / 173653$

Santos, L.A.; Santos, F.H.; Faria, C.M.D.R. Seleção de váriavel resposta para determinação de sensibilidade de isolados de Slternaria spp a Boscalida. Summa Phytopathologica, v.45, n.2, p.213-215, 2019.

O presente estudo teve como objetivo verificar aplicação de diferentes variáveis para determinação da sensibilidade de isolados de Alternaria spp. ao fungicida Boscalida. As variáveis testadas foram inibição do crescimento micelial (ICM), concentração inibitória mínima (CIM) e concentração inibitória a $50 \%\left(\mathrm{IC}_{50}\right)$. Apenas a variável $\mathrm{IC}_{50}$, variável proveniente de análise de regressão, conseguiu discriminar a diferença de sensibilidade dos isolados obtidos de diferentes culturas. Portanto sendo a mais recomendada para estudos com o patógeno.

Palavras-chave: Scott knott, Regressão linear, $\mathrm{IC}_{50}$

\section{ABSTRACT}

Santos, L.A.; Santos, F.H.; Faria, C.M.D.R. Selection of response variable to determine the sensitivity of Alternaria spp isolates to Boscalid . Summa Phytopathologica, v.45, n.2, p.213-215, 2019.

The present study aimed to check the application of different variables to determine the sensitivity of isolates of Alternaria spp. to the fungicide boscalid. The tested variables were mycelial growth inhibition (MGI), minimum inhibitory concentration (MIC) and inhibitory concentration at 50\% (IC50). Only the variable IC50, from regression analysis, was capable of discriminating the difference in sensitivity of the isolates obtained from different cultures. Thus, it is the most recommended variable for studies with the pathogen.

Keywords: Scott knott, Regressão linear, $\mathrm{IC}_{50}$

A família solanaceae compreende espécies vegetais de grande importância para a agricultura. Dentre elas se destacam as culturas da batata (Solanum tuberosum) e do tomateiro (Solanum lycopersicum). O cultivo destas espécies é limitado principalmente por doenças fúngicas, com destaque para pinta preta causada por espécies do gênero Alternaria.

O principal método utilizado no controle desta doença é o controle químico. Entretanto o uso prolongado de uma mesma substância química para controlar doenças, tem resultado no desenvolvimento de resistência em muitos fungos fitopatogênicos. A resistência adquirida é um caráter estável, herdável, que culmina na redução da sensibilidade do fungos ao fungicida (3).

Vários estudos têm sido realizados sobre a resistência deste patógeno, entretanto as pesquisas com resistência apresentam alta variabilidade em suas metodologias e aos testes estatísticos aplicados, bem como as variáveis analisadas. Por exemplo Piqueras et al. (6) realizaram estudos de resistência utilizando como variável resposta o percentual de inibição do crescimento micelial (ICM), Yan et al. (9), em estudos semelhantes utilizaram como variável resposta a concentração inibitória mínima (CIM) e Dube et al. (1), utilizaram a concentração inibitória a $50 \%\left(\mathrm{IC}_{50}\right)$.

Diante do exposto, o presente trabalho visa identificar qual das variáveis, percentual de inibição do crescimento micelial (ICM), concentração inibitória mínima (CIM), concentração inibitória a 50\% $\left(\mathrm{IC}_{50}\right)$, deve ser utilizada em estudos de resistência de Alternaria spp. nas principais culturas solanáceas.

Os experimentos foram conduzidos no Laboratório de Fitopatologia da Universidade Estadual do Centro Oeste - UNICENTRO - PR. Os tratamentos foram os diferentes isolados de Alternaria spp. (Tabela 1). $\mathrm{O}$ delineamento utilizado foi em blocos ao acaso, com cinco repetições. Os experimentos foram repetidos duas vezes no tempo e as análises estatísticas realizadas com as médias dos dados da repetição.

Tabela 1. Descrição dos isolados de Alternaria spp. utilizados no trabalho.

\begin{tabular}{lllll}
\hline Código & Hospedeiro & Cultivar & Ambiente de cultivo & Sistema de manejo \\
\hline Alt 01 & Batata & Ágata & Campo experimental & Orgânico \\
Alt 02 & Batata & Ágata & Campo comercial & Convencional $^{(*)}$ \\
Alt 03 & Tomate & Santa Cruz & Casa de Vegetação & Convencional $^{(* *)}$ \\
Alt 04 & Tomate & Selvagem & Campo experimental & Convencional $^{(* *)}$ \\
\hline
\end{tabular}

${ }^{(*)}$ Sem pulverizações com Boscalida. ${ }^{(* *)}$ Com pulverizações com Boscalida. 


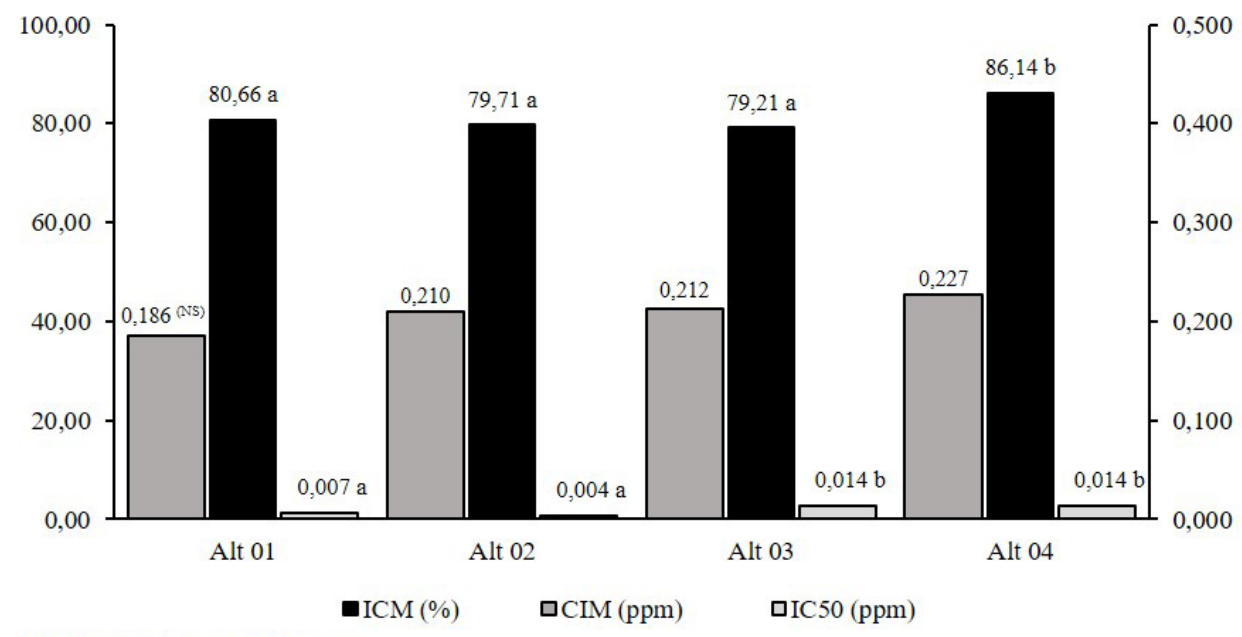

(NS) Variável não siginificativa

Figura 1. Sensibilidade de isolados de Alternaria spp. a boscalida, provenientes de cultivos de batata (Alt01 e Alt02) e tomate (Alt03 e Alt04) em sistemas de produção orgânico (Alt01) e convencional (Alt02, Alt03 e Alt04).

A variável percentual de inibição do crescimento micelial (ICM) foi determinada por meio do crescimento micelial dos isolados de Alternaria spp. em meio de cultura BDA contendo concentração comercial (dose recomendada em bula) de boscalida $(0,25 \mathrm{~g}$ de ingrediente ativo / L).

As variáveis concentração inibitória mínima (CIM) e a concentração inibitória a $50 \%\left(\mathrm{IC}_{50}\right)$, foram calculadas com base na equação de regressão estimada através do crescimento micelial do isolado de Alternaria spp. em meio de cultura BDA contendo diferentes concentrações de Boscalida $(250 ; 25 ; 2,5 ; 0,25 ; 0,025$ e $0 \mu \mathrm{g}$ ia/ml $)$. As placas de ambos experimentos foram mantidas em BOD a temperatura de $25^{\circ} \mathrm{C}$ e fotoperíodo de doze horas. A avaliação do diâmetro da colônia foi realizada cinco dias após a transferência dos discos de micélio para as placas com meio de cultura e o fungicida, período em que a testemunha tomou completamente a placa.

Entre as variáveis analisadas, o percentual de inibição do crescimento micelial (ICM) apresentou diferenças estatísticas em relação aos demais isolados, sendo o isolado Alt04, proveniente de plantas de tomate que receberam aplicação de fungicidas, o que apresentou maior porcentagem de inibição (Fig 1). Embora tenha conseguido discriminar a sensibilidade de apenas um isolado no presente trabalho, o ICM tem sido utilizado para seleção de ingredientes ativos. Fairchild (2) utilizou esta variável para screening de ingredientes ativos para controle de Alternaria solani e Alternaria alternata na cultura do tomate, demonstrando a viabilidade desta variável para trabalhos com esse viés.

A variável concentração inibitória mínima (CIM), não apresentou diferença estatísticas significativas para os isolados testados, não conseguindo discriminar a diferença entre os mesmos. Apesar de não apresentar resultado significativo esta variável é empregada em trabalhos de determinação de eficiência de fungicidas. Trivedi (8) utilizou o CIM para determinação de eficiência de Thiran e Carbendazim no controle de Aspergillus flavus.

A variável $\mathrm{IC}_{50}$ proviniente do ajuste da equação de regressão linear para o comportamento do cresimento micelial dos isolados em diferentes dosagens do fungicidas foi a variável que apresentou melhor discriminação em relação a sensibilidade de isolados obtidos de diferentes culturas, isolados Alt01 e Alt02 provenientes da cultura da batata, e isolados Alt03 e Alt04 da cultura do tomate. A diferença de sensibilidade entre estes isolados deve-se ao fato de que são oriundos de hospedeiro diferentes e principalmente pelo fato de que os isolados Alt01 e Alt02 são provenientes de áreas sem histórico de aplicação de boscalida, áreas de cultivo orgânico e campo comercial que utilizava outro ingrediente ativo. Diversos autores têm utilizados esta variável para estudos de sensibilidade a diferentes fungicidas, Issiakhem et al. (4) para A. alternata, Thobunluepop et al. (7) para A. solani e Khudhair et al. (5) para A radicina.

Como conclusão obteve-se que apenas a variável $\mathrm{IC}_{50}$, variável proveniente de análise de regressão, conseguiu discriminar a diferença de sensibilidade dos isolados obtidos de diferentes culturas e obtidos em áreas com históricos de aplicação de boscalida. Portanto sendo a mais recomendada para estudos de sensibilidade do patógeno a fungicidas.

\section{REFERÊNCIAS}

1. Dube, J.P.; Truter, M.; Van Der Waals, J.E. First report of resistance to QoI fungicides in Alternaria alternata isolates from potato in South Africa. Plant Disease, v.98, n.10, p.1431-1431, 2014.

2. Fairchild, K.L.; Miles, T.D.; Wharton, P.S. Assessing fungicide resistance in populations of Alternaria in Idaho potato fields. Crop Protection, v. 49, p.31-39, 2013.

3. Georgopoulos, S.G. Detection and measurement of fungicide resistancein. In: Dekker, J.; Georgopoulos, S.G. (Ed.). Fungicide Resistance in Crop Protection. Wageningen: Centre for Agricultural Publishing and Documentation, 1982. p.24-31.

4. Issiakhem, F.; Bouznad, Z. In vitro evaluation of difenoconazole and chlorothalonil on conidial germination and mycelial growth of Alternaria alternata and $A$. solani causal agent of early blight in Algeria. PPO-Special Report, v.14, p.297-302, 2010.

5. Khudhair, M. W., Jabbar, R. A., Dheyab, N. S., Hamad, B. S., Aboud, H. M., Khalaf, H. S., \& Mohammed, N. J. Alternaria radicina causing leaf spot disease of date palm (Phoenix dactylifera $\mathrm{L}$.) in Wasit (middle of Iraq) and its susceptibility to bioassay test of two fungicides. International Journal of Phytopathology, v.4, n.2, p.81-86, 2015.

6. Piqueras, C.M.; Herrera, D.; Latorre, B.A. First Report of High Boscalid Resistance in Botrytis cinerea Associated with the H272L Mutation in Grapevine in Chile. Plant Disease, v.98, n.10, p.1441-1441, 2014.

7. Thobunluepop, P., Jatisatienr, C., Pawelzik, E., \& Vearasilp, S. In vitro Screening of the antifungal activity of plant extracts as fungicides against 
rice seed borne fungi. In: Asia Pacific Symposium on Assuring Quality and Safety of Agri-Foods. v. 837. p.223-228, 2008.(Resumo).

8. Trivedi, P., Singh, S., Mishra, J., \& Sinha, A. Minimum Inhibitory Concentration of Thiram and Carbendazim on Aspergillus flavus Of groundnut. Plant
Archives, v.13, n.1, p.393-396, 2013.

9. Yan, H. Yan, H. J., Jurick, W. M., Lou, Y. G., Gaskins, V. L., \& Kim, Y. K. First Report of Pyrimethanil Resistance in Botrytis cinerea from Stored Apples in Pennsylvania. Plant Disease, v. 98, n. 7, p. 999-999, 2014. 